\title{
How Do the Children Manage to Live under Single Parents? A Sociological Study of Cases from Sana'a City, Yemen
}

\author{
Kamel Ahmed Mohammed Alalimi \\ Ph. D. Scholar, Ch. Charan Singh University, Meerut, India
}

\begin{abstract}
Based on ten case studies, this paper seeks for a sociological explanation of the conditions of children who are left with single parents after family disassembly. The study aimed primarily to engage with the issues and impacts of family disorganization focusing on the particular children's plight in Sana'a, the capital city of Yemen.
\end{abstract}

\section{Introduction}

Although family and family disorganization are part of conventional sociological body of literature, familial problems have not much been engaged with due criticality and seriousness in the studies about cities, and it is evident in the sociological studies about Arab world in general. On the other hand, children are most often left as a non serious category for social scientific elaborations. The grim ground reality talks in terms different from the general sense of the issue. The case of the children under single parents of disassembled and disorganized families in the city of Sana'a invites important considerations of sociological analysis and proactive interventions at social, economic, legal and policy levels. After the disassembly of a family due mainly to divorce and sometimes death or disappearance of either of the parent, the social, educational and moral situation of the children is deeply vulnerable. With few exceptions, most of the cases considered here are undergoing through unsupported, hopeless and lonely experiences in their everyday life.By and large frustration at, and antagonism towards larger society grows among them.

As part of a larger study of the family disassembly and its impacts on family, children and society in Sana'a, Yemen, I conducted extensive some case studies in different parts of the city. The focus in themwas largely on two categories such as single parents and children under them. I chose the cases keeping in my mind that the elements to be explained are the causes, factors and impacts of the issue on the family itself, children and on the whole society. Out of them, the children's issue entails particular features that may elaborate the general point of my study.This paper deals particularly with the multi-layered issue of family disassembly from the viewpoint of children under single parents.

\section{Family Disassembly and Affected Children: From the Literature}

Family disassembly has been a key issue in the wider sociological body of literature on family in particular and social problems in general. It has been studied from various different perspectives and using diverse theoretical frameworks. The functionalists who dominated for most part of the discussions in general focused on the problems in performing the roles of members in family, status according to the given roles, and what impact do they haveon the whole social system. The conflict perspective sought to place the problem in the wider context of political economy and to critically explain how problems in family are related to other political and economic conditions in the given society. Exploitations and subordination of female members which led to further imbalances in family came into central position in the feminist point of view. This study is primarily framed in structural-functional perspective, but very importantly without compromising to the issues of changes and economic contexts of the problem in analysis.

Family disassembly is defined in various ways based on differing emphases. Sana Alkhawli defines the family disassembly as the collapse of the family unification and the social role-building while one or more members of the family fail to do their duties and obligations properly (Alkhawli, 1990:275). AtifGhaith in his book Al-mashakil Al-ijtimayia ('Social Problems') defines it as any weakness, mal-adjustment or collapse of the ties in the family community for each other. This weakness is not restricted to that in the relationship between the husband and wife but it includes the relationships between parents and their children (Ghaith, 1979:138). A much preferred definition of family disassembly is that of the well known sociologist, William J. Goode, that it is a phenomenon where the family is not able to perform the main obligations to its members due to some problem such as the death of one or both parents, abandonment or divorce between the espouses'. Goode explained family disorganization as "the break-up of a family unit, the dissolution or fracture of a structure of social roles when one or more members fail to perform adequately their role obligations" (Goode, 1961: 390). Equating marital instability with disorganization William J. Goode has pointed to the fact that unstable families 
as problem-ridden and seen divorce as a "publicly recognized form of marital instability" (Goode,1966: 39-42). Pointing to different facets of the issue at hand, Kamel al-Nahhas, a leading sociologist of family in Arab World, explained the problem of family disorganization as the internal and external state of disorganization that resulted from an insufficient need to a family member, or the whole of the family, that may cause to a pattern of different attitude of individuals, expressed by a single or a group of individuals involved in it in a way opposite to the social goals (Al-Nahhas, as quoted in Algabere and Others, 2001: 124).

The present study considers the different prime characteristics of family disassembly that are charted out in all the definitions mentioned above, although with varying emphasis. However, in the empirical context of this study what was followed in general as the operational definition was as follows: only families with one parent and children considered as a case of family disassembly.

The phenomenon of family disassembly in different time and socio-cultural location shows diverse forms of manifestation, involve multiple factors and goes through various stages, according to wide-ranging causes which are universally recognized as well as particular to cases and contexts. It has several effects primarily on family, and invariably on children most often on larger society too. Among them, the factors involved in, and the effects came out of family disorganization on children entail important sociological implications. which form the core of this study while it deals with their implications on family and society as part. Apart from the studies on family disassembly's forms, stages, causes and effects on family and larger society; there are so far few studies that specifically try to focus on children. But in their general approach children and children's point of view are not taken as vital category and concern of analysis as how they face, perceive and think about the particular problem at familial and social levels. When they are being taken into social scientific account the children are either dealt as part or covered as an obscure, unimportant or dependent category. What can overcome this gap would be an empirically grounded study of family disassembly placing children's experience and perspective at the centre of analysis.

The family is the first seed of the society. The decline or the disassembly is the beginning of the family disintegration and thus is the beginning of the societal disintegration. Thus family is the core of the society and plays a key role in building up good societies (Alessawi, 2004:155).It is the first social system that embraces the child as soon as he/she sees the light of life and the first impact the new-born baby is subject to. On the basis of the family, the child grows up his personality and stances towards society. The person would be normal and right if the family was sound and be not normal if the family was not sound (Rashwan, 2010: 199).Providing the emotional stability for the child within the family and building the family on the basis of intimacy and sympathy and infusing these noble principles will enable the family to be more successful in creating sound people and generations with ideal upbringing (Ahmed, 1999:189).

Family disassembly sometimes leads to the preparation of conditions for family members' delinquency, especially children (Ibrahim, 1998:37-40). When the family gets disassembled and the rally scattered, the individuals get feeling of social insecurity and inability to face up the problems by seeking the easiest way of solution and reaching their goals without reference to how legal is the way used to reach the goals. There is absence of conscience and of adherence to social regulations and standards dominant to guide an individual to the way acceptable to legally achieve the goals. Juveniles from boys and girls are mainly exposed to delinquency and involvement in criminal behavior due to disassembly of their families (Turkiyah, 2004:177).

However, the effects and issues covered generally here and the hitherto unnoticed ones have to be more empirically understood and critically elaborated in order to address the problem also in practical contexts. And the most important question is to understand how children are perceiving and reflecting upon the whole process of family disassembly.

\section{Data and Methodology}

The study has been conducted in different parts of one city, namely Sana'a, the capital of Yemen. Primary data has been collected by using the techniques of interview, observation, and from official government documents. The information about the contact details of the target families for the study was collected by referring to the official registry book of the Social Mission at Sana'a. The Social Mission includes: 1, Social Care House for Boys, 2, The House of Orphans' Care, and 3, Court of South-West Secretariat.

At first the details of the phenomenon of family disassembly were gathered by using case study method. Ten case studies were conducted. Thus the exploratory visit provided help to prepare an interview guide for parents and children separately. At the second stage, data from 100 single parents have been collected by using the interview guide. The case studies were done through two stages. In the first stage, I used interviews, official documents and observations. In the second stage the interview guide or schedule was also used. The interviews with the families were conducted with single parents in their social premises like care centres or offices as well as in their homes. The study aimed at a close understanding and explanation of the causes, factors, and effects of family disassembly from the perspective of children on their everyday life 
situations. The two broader sections in the case studies were single parents and children under them. The children's viewpoint forms the argumentative structure of this study.

In the light of the emerging scenario of family studies (above illustrations) and looking at the academic importance, the present study has sought to examine the family disassembly in the Yemeni Society and its impact on the children, family and society through analytical and comprehensive approach. The study would also look at the reasons and factors behind such family disassembly, as it is one of the sources of instability in a society and its people. The study has focused upon the following specific questions:

1. What are the causes and factors that lead to the family disassembly?

2. What are the impacts of family disassembly on children?

3. What are the impacts of family disassembly on family itself?

4. What are the impacts of family disassembly on society at large?

5. What may be suggestions .i.e. what can be the suitable ways (recommendations) that may help to check this phenomenon? (Suggestions are formulated also from close observations and participatory understanding)

The facts collected through different sources have been analyzed in scientific and systematic manner. Special to the case studies, they were dealt in qualitative analysis. All the data collected by using interview guide/schedule were analyzed by using simple statistical techniques, classifying variables of back ground, causes and effects. Such techniques have helped to arrive at findings on the proposed objectives.

\section{Findings from the Case Studies}

The close observations and intimate conversations that took place in the contexts of the study of ten particular cases could reveal to a large extent the complex dynamics of family disassembly from a hitherto less valued but crucially important angle. They helped me to closely understand and explain how children survive and grow with separated single parents, how they view the causes of the problem, what they think as factors led to the problem, and what are the adverse effects of family disassembly on themselves, their family, and on the wider society. As my study progressed with keen focus on children's perception of problem, I could gather some relevant suggestions too to deal with (and to heal) the problems resulted from family disassembly on practical grounds. The major ones under each classificatory item are briefly elaborated below:

Causes and factors leading to the family disassembly: Divorce stands as the major reason behind the family disassembly which affected the situation of the children in focus. Negative and often continuous intervention of the husband's relatives, frequentquarrels and conflicts between the husband and the wife,the husband's bad treatment to the wife, and the husband's bad economic situation are the mostly found familial causes that led to the divorce and thus to the disorganization of the family. The abandonment and neglect of the wife by the husband, the death of the mother, and the husband's disappearance due to imprisonment are another important causes for family disassembly found among the cases. At times, especially after being attached to the job places and people, theirresponsibly rebellious behavior of the wife towards the situation of husband and care of children causes the disorganization in family. It is also a strong reason for the disassembly that the husband's chronic stressed psychological status which often leads to alcoholismmainly due to loss of business or joblessness.

Effects resulted from the family disassembly on children:The disorganization of family has deep social, moral and psychological impacts on children in several respects. Feeling of insecurity and worry about the future are acute and common to most of the children under study. Children are prone to bad behaviors like smoking and qat-chewing has been found as a consequence of the life in a disorganized family. Amidst the tensions between parents, children happen to take the emotional burdens that develop into their attitude. They feel hatred for the father in response to their bad treatment to their mothers. It was of critical importance to know that, as some children shared, they were laughed at by the society and it had probably damaging effects on their understanding of their self the society as well. Apart from this, scattering of the children between the mother and the father has severe social and personality-level implications on the part of children. Backwardness and failure in the studies, and development of introvert personality structure are found among many children who experience the life of relatively less support and care under single parent after family disassembly.In Some cases the children face cruelty and violence from the new wife of their father.A child's feeling of inferiority and shame because of the imprisonment of his father is beyond the measures of the study. This singleness of the case points to the social rarity of such situations while it also lifts up the veils from the face of a hard and troublesome life condition left for a social being of tender age. This situation has made the child lose his friends and forced him to work for his father who is in jail. Generally found among most children is a psychological effect that is the feeling of isolation and to put up with it. 
Effects resulted from the family disassembly on family:Being so obvious some problems are taken for granted in people's understanding and miss out the gravity of them in the everyday life of those who have to suffer them.One such effect of family disassembly especially in relation to themaintenance of a family which is commonly found in all cases considered in the study is that children were scattered here and there between their fathers and mothers. Apart from being an issue of anxiety for children, it stands as a pervasive concern, negatively and positively, for the separated parents. In many cases the mothers faced the difficulty in upbringing the children. A separated mother with children become a family of economic insufficiencies, and the single parent's trials of meeting the needs of children turn out commonly be burdensome. The single parent family with children growing around faces in most circumstances the insufficiency of the family income.One of the critical and sociologically noteworthy familial issues is that of the matter of socialization process of children in disorganized families. In general the cases show thatthe children would receive various and sometimes contradictory forms or patterns of upbringing. This centrally affects the behavioral dynamics, emotional structure and psychological stability of the children first, and sets heavy duty on the single parent. What is given as preferred value for a child may not always be working in real terms while the child is put between two separated parents. To settle this problem is more troublesome for such a family than it seems in initial perception.After the disassembly, there arise some difficult problems of different types in arise in the family.It is another effect that found in a family after disassembly that the husband is self-satisfied not to re-marry. The separation of the two earning parents has clearly led to the reduction in the family income. In a case of a businessman who got separated with his wife, to take care of the children with him has affected him mainly in terms of maintaining his business. This husband's involvement in taking care of his children has turned out to be neglect of his other businesses.

Effects resulted from the family disassembly on society:There critical effects of family disassembly on society at various levels. The ten cases considered in this study have pointed to some of them with challenging issues. A case revealed itself with a critical social effect of disassembly that the lack of children's visits to the husband's relatives which developed with an attitude of hatred by children towards them. It must be taken as growing problem with enormous social and psychological consequencesthat the children of such families feel inferiority in the society. This is reflected in these children's dealings in their peer groups, and their self perceptions. Similarly, as the intimate contact with a case proved, the insufficient income of the family would lead to the children's feeling of the hatred towards the people around. A macro effect that comes out of the family disassembly the family is that the disassembly bars the development processes of the society. As far as the social and human aspects of development are concerned the disorientation of the children and its causes and consequences around in the background of a family disassembly should genuinely be a social issue of serious attention. One cannot ignore the wider social imbalance around the children who aimlessly wander in the streets. In some cases violence on children is an issue that would be built into the violent formations in social fabric. Least to say, using violence in upbringing the children would create a violence-loving generation. The society's neglect and indifference towards children would create the sense of hatred towards the society, the words of some children of the case sound antagonistic to the general society. As children rebel against the society values and norms the crises appear to have imprints not just at individual level, but on larger social dynamics as well. As products of disorganization and familial imbalances the children grow as complicated people full of anxieties and worries. For the future of any society this is so hopeless a sign and an unproductive pattern of development.

\section{Suggestions Gathered From the Children:}

Each time I faced a case I had to engage with the issues, causes and consequences of a family disorganization on the one side, and I was informed of ideas for applied sociological concerns that the several suggestions to practically deal with the problem on the other side. Although the children were not so pointed in their understanding of the macro picture of the problems involved, and thus were weaker in their suggestions to solve them, clearly they opened up so many clues to handle the issues of children in the backdrop of family disassembly at practical situations.Forming the coherence of arguments and information, and selecting the relevant ones I put some of the suggestions I could gather from the children though in a discrete and incoherent manner. An internally familial in nature but to the local relevance crucially standing suggestion was that no relatives' interference should be entertained in the matters of the couples. The help and support to the disassembled families from outside the family- from the neighborhood, the general people, media, the government and the larger society in general- are general and floating need that came out of the conversations with as well as the close observations of most cases.Another most-felt and sometimes spelt out demand is for the continuity of financial support of the father to the wife and the children even after the divorce. This becomes so important especially when one separated parent gets remarried and leave aside the care and financial support of the children of the earlier relationship. Taking cognizance of developing neglect and criminalization of the children and family of disassembly by society on one hand, and antagonism towards society from the children 
on the other, it must be suggested that disassembled families should be taken with more care and attention by the society, and they should be seriously considered by the state's supporting systems and of social organizations. In cases of remarriage of the separated husband which is more in practice, the complete equality among the wives should be observed by husband.Looking at the imbalances and problems in the family that came mainly out of the basic mismatch between the original spouses, it cannot be helped but said that the partners should carefully select their other partners. A very practical consideration which would be effective in many such circumstances and closer to legal and policy interventions would be the argument that the couples should share the responsibilities of children's care and house affairs. And finally, there is an apparent need for care centers to be opened for children and families of disassembly for solving problems related to social, economic, and psychological conditions of the members of the family in general and children in particular.

\section{Conclusion}

The study has pointed to some concrete and particular circumstances and consequences of family disassembly while it shows some bearings on the earlier sociological literature on the issues closely or loosely related to it. While the major earlier studies two based on the empirical context of Yemeni society; and two others, one on Emirates' social contexts and the other on Qatari background, focused on the delinquency-aspect of children's behavior in the contexts of family disorganization and social transformation, the present empirical study gave more voice to children. This has helped to explain the situation providing viable thoughts and workable clues for practical measures to deal with problem. Some of the findings are similar to that of the existing literature, such as divorce as the major reason of family disassembly and adverse effects of it on the behavior of children and development of backwardness in the social development patterns as a general social effect of it. On the other hand, the present study has some of its own findings such as imprisonment and joblessness of the father, or unwanted interventions of the relatives in the internal issues of the husband and wife as reasons for family disassembly; adverse effects of it on the self-perception and perception of society by the children of disorganized family etc. What is so remarkably revealed through this study is when children are heard, empowered with words about themselves, their families before and after disassembly, and about society that mostly indifferent to them, they are able to point to many a nuance of already explored and ignored phenomena. Moreover, they try to comprehend the problems around them and seek to reflect proactively upon them when they are given chances. They also helplessly know that they are prone to delinquency and also they are perceived as delinquents, but all the judgment of society fall upon condemning them to silence and denying them a chance for a word about their world of helplessness. To these children a non-normal life of being under a single parent was imposed in passivity when it took place, they are mostly not conferred the status of activity to convey the reality within and without them.

\section{Bibliography}

[1] Ahmed,Garheb.M., 1999: The Crime and Juvenile Delinquency (the First Edition, part 2, 4, in Arabic), Alexandria, The Scientific Office for Print and Distribution, Egypt

[2] Alessawi, Abdulrahman, 2004 : The Family Psychology : The Problems and The Guide Programmes (in Arabic), Amman, Dar Osama for Press

[3] Algabere, Ameena, and Others, 2001 : “The Family Disassembly: Causes and Suggesting Solution” (in Arabic), Nation Book, No. 83, Qatar

[4] Alkhawli, Sana, 1990: The Marriage and The Family Relationship (in Arabic), Alexandria, Dar Almarifa Aljamia.

[5] Alshaafi,M., 2006 : The Family Disassembly and Its Impact on the Juvenile Delinquencies, M.A. Thesis (in Arabic) Department of Social Sciences, Riyadh, Naïf University.

[6] Ghaith, Mohammed. Attif, 1979 : Dictionary of Sociology (in Arabic), Alexandria, The General Egyptian Authority for Book

[7] Ibrahim, AkramNasha'at, 1998 : The Sociology of Crime (First Edition, in Arabic), Baghdad: Iraq, Alneizak Printer

[8] Isa,MunaJuma, 1989 : The Family and Juvenile Delinquency in Society of Emirates, M A, Thesis Unpublished (in Arabic), Cairo, Cairo University

[9] Rashwan, Hasan Abdulhamid, 2010 : Study of Criminal Sociology (Second Edition, in Arabic), Alexandria, The Modern University Office

[10] Turkiyah, Bahaaddin Khalil, 2004: The Family Sociology (in Arabic), Damascus, (Syria), Alahali William J. Goode, 1961: Family Disorganization, in Contemporary Social Problem, Ed. By Robert K. Merton and Robert A. Nisbet, New York: Harcourt Brace.

[11] William J. Goode, 1966 : Marital Satisfaction and Instability, New York: Collier MacMillan

[12] Tomim, K.A., 1997 : Patterns of Social Change and Patterns of Misdemeanors in The Yemeni Society (in Arabic) Ph. D. Thesis, Department of Sociology, Cairo, Ain Shams University 